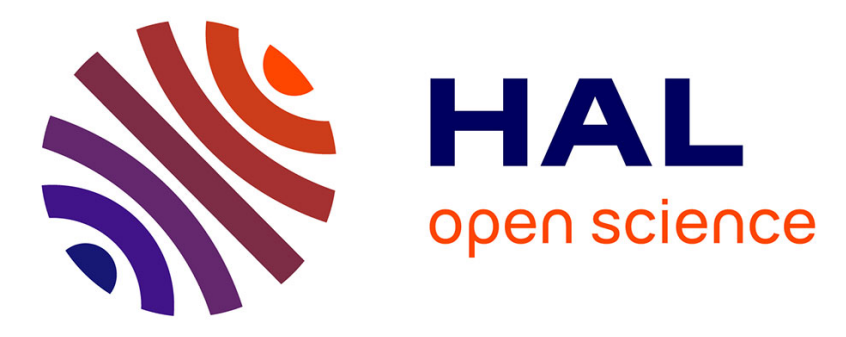

\title{
Preference Theory and Low Fertility: A Comparative Perspective
}

Agnese Vitali, Francesco C. Billari, Alexia Prskawetz, Maria Rita Testa

\section{To cite this version:}

Agnese Vitali, Francesco C. Billari, Alexia Prskawetz, Maria Rita Testa. Preference Theory and Low Fertility: A Comparative Perspective. European Journal of Population / Revue européenne de Démographie, 2009, 25 (4), pp.413-438. 10.1007/s10680-009-9178-x . hal-00535472

\section{HAL Id: hal-00535472 https://hal.science/hal-00535472}

Submitted on 11 Nov 2010

HAL is a multi-disciplinary open access archive for the deposit and dissemination of scientific research documents, whether they are published or not. The documents may come from teaching and research institutions in France or abroad, or from public or private research centers.
L'archive ouverte pluridisciplinaire HAL, est destinée au dépôt et à la diffusion de documents scientifiques de niveau recherche, publiés ou non, émanant des établissements d'enseignement et de recherche français ou étrangers, des laboratoires publics ou privés. 


\title{
Preference Theory and Low Fertility: A Comparative Perspective
}

\author{
Agnese Vitali · Francesco C. Billari • \\ Alexia Prskawetz $\cdot$ Maria Rita Testa
}

Received: 6 February 2008/Accepted: 9 January 2009/Published online: 17 February 2009

(C) Springer Science+Business Media B.V. 2009

\begin{abstract}
The discussion on the causes of the most recent fertility decline in Europe, and in particular on the emergence of lowest-low fertility, emphasizes the relevance of cultural factors in addition to economic ones. As part of such a cultural framework, the heterogeneity of preferences concerning the "career vs. family" dichotomy has been systematized in the "Preference Theory" approach developed by Catherine Hakim. This heterogeneity in preferences, however, has so far been underinvestigated in a comparative framework. This paper makes use of comparative data from the 2004/2005 Round of the European Social Survey to test the links between individuallevel preferences and both fertility outcomes and fertility intentions, in a variety of societal settings. Results confirm an association between work-family lifestyle preferences and realized fertility in a variety of European countries, while they do not show a relationship between lifestyle preferences and fertility intentions. Results further support the existence of heterogeneous patterns of association between lifestyle preferences and fertility choices among welfare regimes.
\end{abstract}

Keywords Preference Theory · Low and lowest-low fertility · Europe · European Social Survey · Welfare regime

\footnotetext{
A. Vitali $(\bowtie)$

Carlo F. Dondena Centre for Research on Social Dynamics, Università Bocconi, Milan, Italy

e-mail: agnese.vitali@unibocconi.it

F. C. Billari

Carlo F. Dondena Centre for Research on Social Dynamics, IMQ and IGIER, Università Bocconi, Milan, Italy
}

\section{A. Prskawetz · M. R. Testa}

Vienna Institute of Demography, Austrian Academy of Sciences, Vienna, Austria

\section{A. Prskawetz}

Institute of Mathematical Methods in Economics, Research Unit Economics, Vienna University of Technology, Vienna, Austria 
Résumé Le débat portant sur les causes de la baisse la plus récente de la fécondité en Europe, et en particulier sur l'émergence des fécondités les plus basses met l'accent sur le rôle des facteurs culturels, par-delà les facteurs économiques. Dans le cadre de ces facteurs culturels, l'hétérogénéité des préférences en matière de dilemme «carrière ou famille» a été formalisé par Catherine Hakim sous la forme de la «théorie des préférences». Cette hétérogénéité des préférences a toutefois été peu explorée dans une perspective comparative. Cet article exploite les données comparatives de la vague 2004/2005 de l'Enquête Sociale Européenne pour tester les liens entre les préférences individuelles, d'une part, et la fécondité réelle et souhaitée, d'autre part, dans des contextes sociaux très divers. Les résultats confirment une association entre les préférences en matière de mode de vie par rapport au travail et à la famille et la fécondité réelle dans toute une série de pays européens, mais ne mettent pas en évidence de lien entre les préférences en matière de mode de vie et la fécondité souhaitée. De plus, les résultats confirment l'existence de schémas hétérogènes d'association entre les préférences en matière de modes de vie et les choix de fécondité dans les différents régimes d'Etat-providence.

Mots-clés Théorie des préférences · Fécondités les plus basses · Europe · Enquête Sociale Européenne · Régime d'Etat-providence

\section{Introduction}

The emergence of very low and lowest-low fertility in Europe during the 1990s and in South-Eastern Asia during the early 2000s has posed several challenges to the scholars who use international comparison as a way to shed light on the causes of differences in fertility patterns (see, e.g. Caldwell and Schindlmayr 2003; Kohler et al. 2002). Moreover, the increasing relevance of low fertility levels in the policy debate in Europe and elsewhere has triggered the need for a deeper understanding of the diverse determinants of fertility choices as they might imply different policy choices (Demeny 2003; Castles 2003; Commission of the European Communities 2005; McDonald 2002; Stark and Kohler 2002). Roughly speaking, contributions that aim at explaining the causes of very low and lowest-low fertility may be grouped into two main categories. First, a structural approach, which provides explanations based on economic factors like rising female education and labour supply, policy changes and responses to actual and expected unemployment and to the general economic conditions (see, e.g. Adsera 2005; Ahn and Mira 2002; Butz and Ward 1979). Second, a cultural approach, centred around the notion of Second Demographic Transition, which stresses ideational factors like changing values and attitudes, increased female autonomy and independence as the main driving forces behind fertility decline (see, e.g. Lesthaeghe 1983; Van de Kaa 1987). Some authors have emphasized the need to stress simultaneously structural and cultural determinants (see, e.g. Lesthaeghe and Surkyn 1988; Stark and Kohler 2002). Nevertheless, so far no comparative study has been conducted with the aim of weighing the relative importance of the two sets of factors in different European 
countries. To this end, it is necessary to exploit the heterogeneity in fertility behaviour that exists across countries, and to have access to comparative microlevel data that contain both structural and cultural variables.

In this paper, we exploit a new source of data, the 2004/2005 Round 2 of the European Social Survey (ESS-2), in order to conduct a comparative analysis of fertility choices and intentions for 11 European countries, that we group according to a well-known classification based on the idea of welfare regimes. Our analysis starts from Hakim's (2000) proposal of "Preference Theory." Preference Theory gives a central role to the heterogeneity of lifestyle preferences within a population in the explanation of family and fertility choices, and, in general, choices that affect the work-family link. More specifically, the paper investigates the link between women's lifestyle preferences and fertility outcomes and intentions. Results show that the classification of women proposed by the Preference Theory is able to identify three different categories of women according to their work-family lifestyle preferences in a variety of European countries. Empirical analyses confirm an association between preferences and actual fertility, while they do not support the association between preferences and fertility intentions. Results further show the existence of heterogeneity among welfare regimes for what concerns the relationship between lifestyle preferences and fertility choices. The remainder of the paper is organized as follows. First, we briefly review Preference Theory and the critical discussion it has generated in recent sociological and demographic research. We then describe the ESS-2 data on which our empirical analyses are based and discuss the links between Preference Theory and the ESS-2 survey instruments. After providing some descriptive evidence and illustrating our analytical approach, we present the main results. Finally, we provide some concluding remarks and a general discussion.

\section{Preference Theory and Fertility Choices}

Catherine Hakim's "Preference Theory" (Hakim 2000; see also Hakim 2003a, b) is a sociological theory which aims to explain the changes that women have experienced in contemporary societies according to two main lifecycle patterns: fertility and employment. Preference Theory regards lifestyle preferences and values as the principal determinants of women's fertility choices and outcomes, and it emphasizes the importance of cultural factors as the key factors behind the recent changes in family and fertility that have occurred in all modern industrialized societies. Preferences obviously also shape men's decisions, but "attitudes have an especially strong impact on women's behaviour because women have genuine choices to make regarding employment versus home-making" (Hakim 2002, p. 432).

An attempt to apply the Theory explicitly to the masculine universe can be found in Rabušic and Manea (2006). According to Hakim, in modern industrialized societies women are heterogeneous and this heterogeneity should be considered explicitly in the explanation of behaviour as well as in the design of 
public policies. More specifically, three different "types" of women are identifiable in terms of their lifestyle preferences with respect to the trade-off between family and work. The idea is that, within an industrialized country, the distribution of women between the three groups is roughly symmetric. At the two extremes, both accounting for 10-30\% of the total, there are, respectively, familyand career-oriented women, while the great majority, between 40 and $80 \%$ of the total, are defined as "adaptive women." Preference Theory provides a detailed description of the three types' identities.

Being family oriented means regarding family life and children as the main priorities in life, thus, deciding not to work, at least unless pushed to enter the labour market by economic need. As some of these women obtain high levels of education, this can be interpreted as a means to earn a better position on the partnership market and, more generally, to earn some kind of cultural capital. Being career oriented, on the other hand, means giving value to a life devoted to work, either in paid employment or in the public arena. Career-oriented women strive for a high level of education, and they stay frequently unmarried and/or childless. Finally, adaptive women have no prevailing preference orientation. They usually want to get the best of both worlds, combining work and family. Adaptive women are therefore in the very centre of the trade-off between family and work career. The group of adaptive women usually also includes women with an unplanned future, who aim at grasping career or family opportunities when either one of the two shows up, or when public policies change in favour of one extreme group or the other. Women in this group usually achieve education and qualifications as an insurance policy and usually quit working or move to part time work after a birth. This is the category that researchers usually refer to when they consider women in a given society as belonging to a homogeneous group.

According to Preference Theory, the three lifestyle orientations originate within a new scenario that results from five historical changes: the contraceptive revolution, the equal opportunities revolution, the expansion of white-collar occupations, the creation of jobs for secondary earners and, finally, the increasing importance of personal values and preferences when individual choices are made. In other words, the emergence of this new scenario can be interpreted in terms of the Second Demographic Transition, as outlined by Lesthaeghe and Van de Kaa in a series of contributions, with the difference that Hakim puts a specific emphasis on the resulting within-society heterogeneity of preferences rather than on the commonality of trends.

Hakim points out that not all modern societies have achieved the new scenario yet $^{1}$ and that the relative size of the three groups of women could vary in those countries where public policies favour one group or another. In her view, on their

\footnotetext{
1 "The US, Britain and probably the Netherlands currently provide the prime examples of societies that have achieved the new scenario for women. [...] Most European countries still have little or nothing to actively enforce equal opportunities legislation. [...] For example, in Greece, Italy and Spain, there is evidence of informal barriers to women's access to the labour market: female unemployment rates are more than double those of males [...]. Within the European Union, only Britain, Ireland, and the Netherlands have a public body responsible for enforcing equal pay and equal opportunities laws" (Hakim 2003b, p. 360).
} 
own, preferences "have a strong impact on behaviour: on employment rates, hours worked, fertility, and patterns of marriage and divorce" (Hakim 2003c, p. 342). Moreover, contextual social, structural and institutional factors influence different groups of women in different ways: adaptive women are very responsive to any kind of public policies and to institutional factors generally, but the other two extreme groups are influenced only by factors affecting their inner preference orientation, i.e. family-oriented women are not responsive to employment policies while careeroriented women are not responsive to social family ones.

According to Hakim, within the European environment, Britain seems to be a special case where the labour market, the legal system and the background acceptance of differences in values and cultures have all contributed to the emergence of the new scenario for women. Moreover, Britain can be regarded as the most suitable background for testing Preference Theory also because, given the limited scope of welfare policies, the Government's intervention in the private sphere acts without biasing individual decisions. Indeed, Hakim provides evidence that her classification fits the British case quite well, and that it also fits actual fertility in Britain: family- and work-centred women turn out to be, respectively, the most and the least fertile.

Hakim's Preference Theory has attracted a great deal of interest in the literature, including critical views. The main critiques concern the causality link, i.e. whether heterogeneous preferences are actually causing heterogeneous behaviour. Instead, Hakim's critics suggest that the causality link goes in the opposite direction, i.e., generally, person-specific circumstances and background factors mostly account for a person's orientation in life and thus determine decisions, while preferences do not causally explain behaviour, but just shape and influence choices (Crompton and Harris 1998; Fagan 2001; Procter and Padfield 1999; Rose 2001). It is well known from the literature that actual fertility might trigger changes in values and preferences (see, e.g. Beets et al. 1999). In other words, family-oriented women might not tend to become more frequently married with children; it might be that the circumstance of being mothers with children causes preferences to be oriented toward a family-centred lifestyle. In this respect, McRae's critique (2003a, b) underlines that Preference Theory does not sufficiently take into account the fact that situational, structural and normative constraints might bias women's choices, lifestyle preferences being susceptible to change over the life course. The same concept has been outlined by Tomlinson (2006), who observes that care networks, work status and the welfare policy context are three powerful forces which can either facilitate or impede the realization of every woman's work preferences, driving female trajectories toward and away from part-time work following maternity. Doorewaard et al. (2004), focusing on a sub-sample of female returners ${ }^{2}$ and analyzing women's orientations toward work-i.e. different reasons driving women's (re)entrance in the labour market-demonstrate a strong association between personal, financial and family constraints and women's work orientations.

\footnotetext{
2 The expression "female returners" refers to "women who seek to re-enter the work-force after a few years of unpaid care-taking responsibilities" (Doorewaard et al. 2004, p. 8).
} 
Others discussed whether the heterogeneity in preferences could be broader than the three categories proposed by Hakim (Aassve et al. 2007; Tomlinson 2006).

In what follows, we attempt to build a categorization of women that comes as close as possible to the one outlined by Hakim, and we investigate whether three different types of women are identifiable when extending the analysis to European countries other than Great Britain. Subsequently, we test whether actual and intended fertilities are different across these three groups as suggested by the Preference Theory.

\section{Comparative Survey Data and the Classification of Women According to Work-Family Preferences}

Our empirical analyses are based on the European Social Survey Round 2 2004/ 2005, second edition (ESS-2 from now onwards). ${ }^{3}$ The ESS is a biennial social survey that generally aims at measuring values and behaviours of European populations and at understanding how and why such patterns can vary over time. The questionnaire for each round consists of a core module, constant from round to round, plus rotating modules, repeated at intervals and each time devoted to different topics. The core module aims at monitoring change and continuity in socio-economic-political and demographic variables, and at providing background variables for the analysis of the rotating modules, whose purpose is to investigate in depth some particular themes. The European Social Survey proves to be useful for our analysis of lifestyle preferences since, within the second round (ESS-2), it contains a rotating module collecting information on family, work and well-being. Therefore, specific questions about family-work balance are asked, as well as general questions on family and fertility choices. Particular care has been taken in developing the international comparability of the ESS. More specifically, the data are collected through a cross-sectional survey, conducted through face-to-face interviews in national languages with a strict methodology and with careful translation of questionnaires that ensures the comparability of national samples.

ESS-2 allows us to design a classification of women that reproduces the one developed by Hakim, by looking at their expressed preferences about the combination of family and work, instead of distinguishing women according to observable variables, such as, for example, the first time mothers' work history proposed by McRae (2003a). In the latter case, in fact, behaviour is used to predict preferences, and not, as Preference Theory suggests, the other way round. However, our cross-sectional data do not allow us to discriminate between the two causality directions. Hakim's original classification of women into the three groups, namely family-oriented, career-oriented and adaptive, was based on three survey questions. She referred to the 1999 British Survey, a project carried out for an Economic and Social Research Council Programme on the Future of Work, and developed with the

\footnotetext{
3 Edition 2.0, with data released on 8 March 2006. The original dataset includes all countries for which data have been deposited before 1 June 2005: Austria, Belgium, Czech Republic, Denmark, Estonia, Finland, Germany, Greece, Luxembourg, Norway, Poland, Portugal, Slovenia, Spain, Sweden, Switzerland, United Kingdom, France, Hungary, Iceland, Ireland, Netherlands, Slovakia, Ukraine.
} 
precise purpose of testing Preference Theory. Using a question on ideal family models, Hakim identifies home-centred women as those preferring complete role segregation within marriage, with the man as the breadwinner. ${ }^{4}$ Career-oriented women are identified by combining their preference for the egalitarian family model with other two questions. First, Hakim uses an indicator of work commitment: the statement that one will continue with paid work in the absence of economic need. ${ }^{5}$ Then, she combines the previous information with the status of being a primary earner, i.e. the sole or joint main earner in the household. ${ }^{6}$ Adaptive women are defined as the residual category. The present classification is that presented by Hakim (2002, p. 442). In subsequent articles (see, for example, Hakim 2003b, p. 362), however, she omits the reference to the choice of a particular family model when identifying career-oriented women.

Within the ESS-2 (which was not explicitly designed to conform to Hakim's categorization), we use a set of three questions to build a classification of women's lifestyle preferences. More specifically, we use a question about the male versus female eligibility to enter the labour market when jobs are scarce, and code as family oriented those women agreeing or strongly agreeing with the following statement "When jobs are scarce men should have more right to a job than women." In this way, we identify women supporting a traditional view of the family with clear division of gender roles. For the identification of career-oriented women, we rely on two questions. First, we code as "committed to work" those women who disagree or strongly disagree with the following statement: "A woman should be prepared to cut down on her paid work for the sake of her family." The question on work commitment identifies women with a manifest job prioritization, for whom "family life is fitted around their work" (Hakim 2003a, p. 357). Then, following Hakim, we use a question asking the proportion of the household income provided by the respondent, and code as primary earners those answering that they provide from about half to all of their household income. Combining the previous information, we define the work-centred group. The inclusion of the income variable as an indicator for identifying career-oriented women needs to be read in terms of adoption of "a primary earner identity" (for a more detailed explanation, see Hakim 2003b, p. 363). Women who do not have a partner and thus are more often primary earners, are not automatically classified as work oriented, the latter

\footnotetext{
4 The survey question used is the following: "People talk about the changing roles of husband and wife in the family. Here are three kinds of family. Which of them corresponds best with your ideas about the family?

- A family where the two partners each have an equally demanding job and where housework and the care of the children are shared equally between them.

- A family where the wife has a less demanding job than her husband and where she does the larger share of housework and caring for the children.

- A family where only the husband has a job and the wife runs the home.

- None of these three cases."

5 The survey question used is the following: "If without having to work you had what you would regard as a reasonable living income, would you still prefer to have a paid job, or wouldn't you bother?"

6 The survey question used is the following: "Who is the main income-earner in your household? Is it yourself? Your partner/spouse? Both of you jointly? Or someone else?"
} 
Table 1 Classification of women according to work-family preferences: a comparison of frequencies using the 2004 ESS-2 for Britain and Hakim's (2003b) 1999 ESRC $^{\text {a }}$ survey (column percentages)

ESS-2, 2004

ESRC, 1999

\begin{tabular}{lrr}
\hline Family-oriented & 16 & 14 \\
Adaptive & 68 & 70 \\
Career-oriented & 16 & 16 \\
No. of cases & 601 & 1,235 \\
\hline
\end{tabular}

Note: For a better comparison with Hakim's result, we replicate her sample restrictions referring to women aged 20-59 years, having completed their full-time education

${ }^{a}$ Economic and Social Research Council (ESRC) Research Programme on the Future of Work, running over 1998-2003 in Britain

category being defined via a combination of the information on income and work commitment. We classify other respondents as adaptive. ${ }^{7}$

Two of the three questions involved in our classification concern attitudes about gender roles on family and market work. Their use for this purpose could thus be criticized (see Hakim 2003c), because preferences may be not properly captured when general beliefs and approvals are asked as indicators of personal goals and attitudes. Nonetheless, this study demonstrates an association between the orientations expressed when answering these questions - although they could be driven by public morality suggestions - and a series of observable characteristics in a woman's family and working life.

Our classification of preferences seems indeed to closely replicate Hakim's classification for Britain. In fact, 2004 ESS-2-based results for Britain-obtained by considering the same sample restrictions as Hakim (2003b) — are very similar to the one based on the 1999 British survey developed by Hakim (Table 1).

\section{The Comparative Setting and Descriptive Evidence}

Our comparative analyses focus on Western Europe only. In order to grasp the link between preferences and behaviour as mediated by the policy environment, we refer to the widely used "three worlds" classification of Western European countries according to their welfare regimes, originally developed by Esping-Andersen (1990). As is commonly done, this typology is modified to create a specific fourth group for Southern European countries (see, among others, Ferrera 1998; Ferrera et al. 2000; Esping-Andersen et al. 2002 and Gauthier 2002). More specifically, we use data from the following 11 European countries: Austria, Germany, Switzerland, Great Britain, Ireland, Spain, Portugal, Greece, Sweden, Denmark and Norway. We thus make use of four groups of countries:

\footnotetext{
${ }^{7}$ Forty respondents were classified both as family-oriented and as career-oriented. Actually, the questions used for classifying women are not mutually exclusive. Moreover, all the three questions used are opinion questions, so the answers could be driven by social norms rather than by the respondents' subjective ideals. For instance, while men usually define themselves as primary earners even when they are actually not, women sometimes answer in the opposite direction-cf. Hakim (2003b, p. 363) for a similar argument. For the remainder of this analysis, these cases will be excluded.
} 
- Liberal Welfare Countries, i.e. Great Britain and Ireland. Such countries offer relatively low welfare coverage and focus primarily on cases of poverty and need, with eligibility also verified through means testing. This system thus relies on the market as the main provider of welfare services, besides the family-for this reason Hakim considers this regime not to bias individual choices within Preference Theory.

- Social Democratic Welfare Countries, i.e. Sweden, Denmark and Norway. These countries are characterized by a universalistic regime that aims at promoting equality between individuals in general and between women and men in particular. This regime offers social services and benefits to all its citizens, as well as specific rights related to employment. When compared to other welfare regimes, this regime has the highest proportion of public expenditure devoted to welfare. The State is therefore the main provider of welfare services.

- Conservative Welfare Countries, i.e. Austria, Germany and Switzerland. These continental countries provide an "intermediate" level of welfare, differentiated with respect to marital status or to the years of contribution to the social security system and frequently linking welfare benefits provision to working status. In this regime, the family is seen as the main welfare provider and the family idea is in line with the traditional gender division of tasks and the "male breadwinner" model.

- Southern European (Familialistic) welfare countries, i.e. Spain, Portugal and Greece. In these countries, welfare relies both on public and private services and provides a very fragmented set of policies usually dependent on the individual's working status. These countries share similarities with the Conservative cluster (and for this reason they are grouped together in the original "three worlds" classification by Esping-Andersen), but for Southern European countries, the role of the family as the principal welfare provider is even more relevant. We know that lowest-low fertility emerged during the 1990s in this cluster (Kohler et al. 2002). ${ }^{8}$

We restrict our analyses to the ESS-2 sub-sample of female respondents aged 45 years or less. For these women, the information on short-term fertility plans is available; this allows us to use the same sample for analyzing both actual and intended fertility. ${ }^{9}$ The final sample includes 5,529 female respondents for 11 countries. In the remaining part of the section, we discuss some descriptive results. According to Hakim's classification, the percentage of home- and work-centred groups should vary between 10 and $30 \%$, while adaptive women are in the range of 40-80\%. By applying the ESS-2-based classification to all 11 European countries considered in the analysis, we find a distribution that lies, on average, within the bounds suggested by Hakim (Table 2).

\footnotetext{
${ }^{8}$ Unfortunately, we could not consider Italy in this study, since Italian data were not comparable with other ESS-2 data.

9 The question on fertility intentions is asked only to women aged 45 years or less. We also exclude from our analyses observations for which the relationship of the respondent with other household members is missing, when the respondent is not the only person in the household.
} 
Table 2 Classification of women according to work-family preferences using the ESS-2 (row percentages)

\begin{tabular}{lllll}
\hline & Family-oriented & Adaptive & Career-oriented & No. of cases \\
\hline Liberal & & & & \\
Britain & 12 & 71 & 17 & 472 \\
Ireland & 13 & 76 & 11 & 525 \\
Social Democratic & & 59 & 38 & 370 \\
Denmark & 3 & 65 & 33 & 442 \\
Sweden & 2 & 70 & 26 & 417 \\
Norway & 4 & & & \\
Conservative & & 72 & 16 & 675 \\
Germany & 12 & 76 & 14 & 617 \\
Austria & 10 & 78 & 10 & 534 \\
Switzerland & 12 & & & 571 \\
Southern European & & 57 & 15 & 400 \\
Greece & 28 & 66 & 13 & 506 \\
Spain & 21 & 63 & 10 & 5,529 \\
Portugal & 27 & 69 & 17 & \\
Whole sample & 14 & & & \\
\hline
\end{tabular}

Note: Within each regime, countries have been ordered with respect to the proportion of work-oriented women in a descending order

At the country level the distribution of women's preferences lies outside the predicted range or is very close to its bounds. These "deviations" can be considered as consistent with Preference Theory, since they support Hakim's hypothesis that in some countries public policies might trigger the distribution of preferences towards giving more weight to a specific group. Indeed, this seems to be the case in all countries belonging to the "Social Democratic" and to the "Southern European" welfare regimes. In the first group, the percentage of career-oriented women is the highest, accounting for $26-38 \%$ of all women in the sample. At the same time, the proportion of family-oriented women in countries belonging to the "Social Democratic" welfare regime is the smallest and it lies below the lower bound of $10 \%$, as suggested by the Theory. Hakim suggests that Sweden lacks genuine choices because of the slowdown of two of the five structural changes that have occurred in all modern societies: the creation of jobs for secondary earners and the importance of values and attitudes (Hakim 2002) and, more generally, because of Swedish fiscal and social policies (Hakim 2008). Indeed, it is easy to conclude that all countries of the Social Democratic regime share public policies aiming at favouring women's entrance in the labour market in a context of gender equality, which has facilitated and supported the combination of childrearing and labour market participation. Social norms and values have furthermore fostered the establishment and acceptance of those policies.

The proportion of family-oriented women in the three Southern European countries is concentrated on the upper bound, varying between 21 and $28 \%$. In this 
case, the size of the work-oriented group shows no difference with respect to other European countries: it is the percentage of adaptive women that is reduced. According to Preference Theory, the idea is that labour market conditions and social norms have contributed to slowdown historical changes: what matters here is the presence of "informal barriers to women's access to the labour market" (Hakim 2000 , p. 455) and the slow change in values and attitudes. Indeed, in Southern European countries, women's lifestyle choices are still closely shaped by tradition, social habits and mental architectures embedded in culture and in daily life, see, e.g. the "strong family" tradition (Reher 1998). Overcoming these family-oriented constraints might take more time with respect to other European countries.

To sum up, Hakim's classification is consistent with the peculiarities of Social Democratic and Southern European countries as discussed in the literature on welfare regimes. However, no specific difference can be discerned between the preference distribution in the Liberal and in the Conservative countries.

From a descriptive point of view, the classification by Hakim seems to clearly identify three distinct groups of women, who differ with respect to several items (see Table 3). The proportion of women employed in paid work is the highest within the work-oriented group (81\%), while only less than half of the women classified as family-oriented are working (46\%). Adaptive women are in between. At the individual country level, in some cases, this rank does not hold: in Denmark the same percentage is observed for both career- and family-oriented women, while in Norway and in Switzerland the percentage of family-oriented women who are currently employed is (slightly) higher than that of adaptive women. In this regard, beside the above-mentioned ease of female entrance into the labour force experienced by these countries, it is necessary to consider the fact, documented also by Hakim, that sometimes women enter the labour market because of financial needs, even against their preferences. When considering the mean number of years of completed full time education, career-oriented women study, on average, 1 year more than adaptive women and 3 years more than family-oriented women. The differences are not too pronounced, however, confirming Hakim's idea that the three divergent lifestyle preferences can be found at all educational levels and in all social classes.

The great majority of family-oriented women are married or cohabiting (69\% within the whole sample), while only half of work-oriented women are currently living with a partner (50\%). Again, the adaptive group is in between. Again, Denmark departs from the general average behaviour, since no clear difference between the three groups can be discerned. On average, a majority of familyoriented women $(62 \%)$ engage in housework for more than half of the total household time devoted to this activity; this proportion gradually decreases when considering adaptive (48\%) and work-oriented women (32\%). At the individual country level, only Denmark departs from the expected relationship. Finally, the percentage of family-oriented women claiming they improved their knowledge or their skills in the last year only accounts for a share of $23 \%$, on average. The same percentage increases by 20 points percent when considering adaptive women and reaches $58 \%$ when considering career-oriented women. 


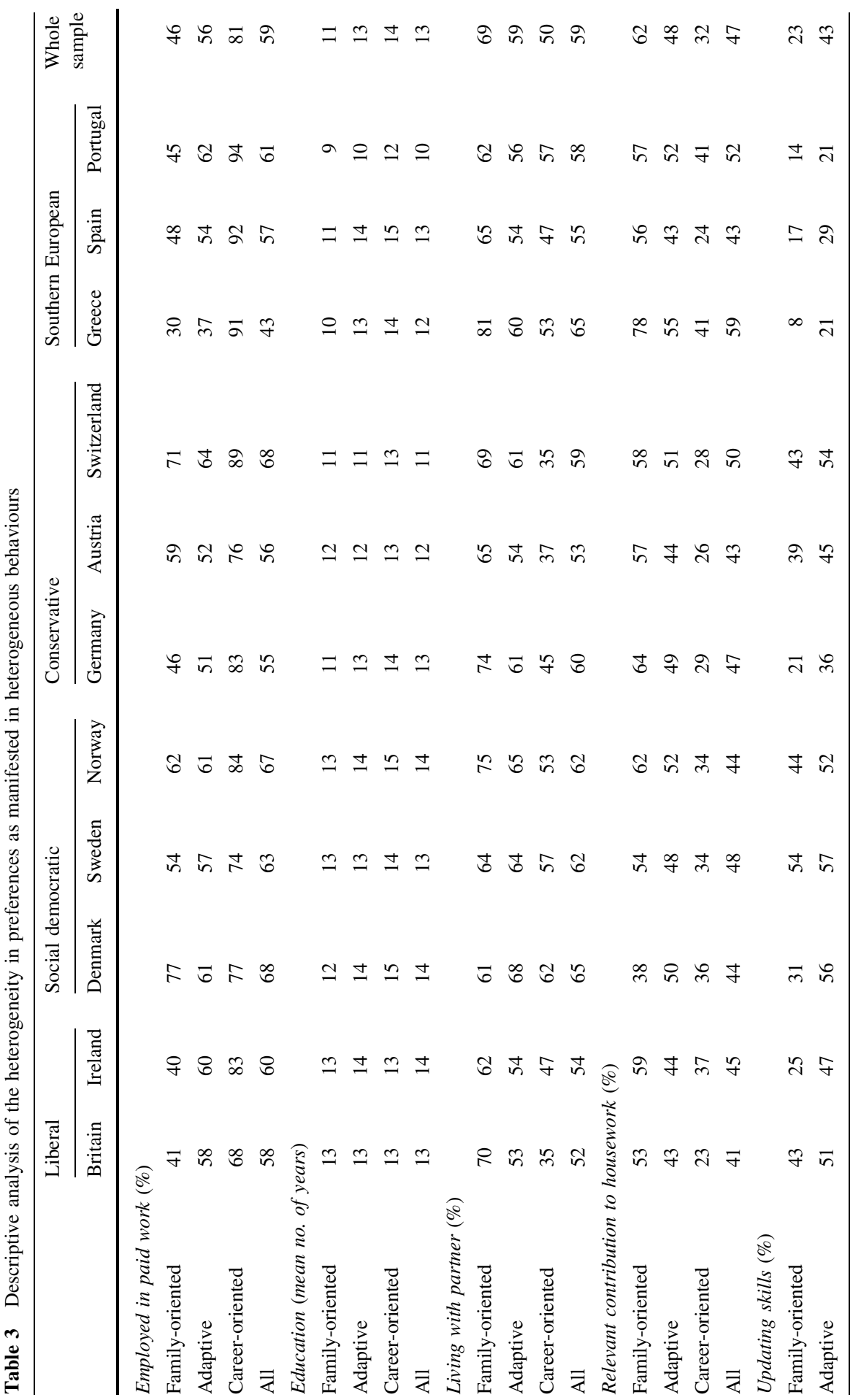




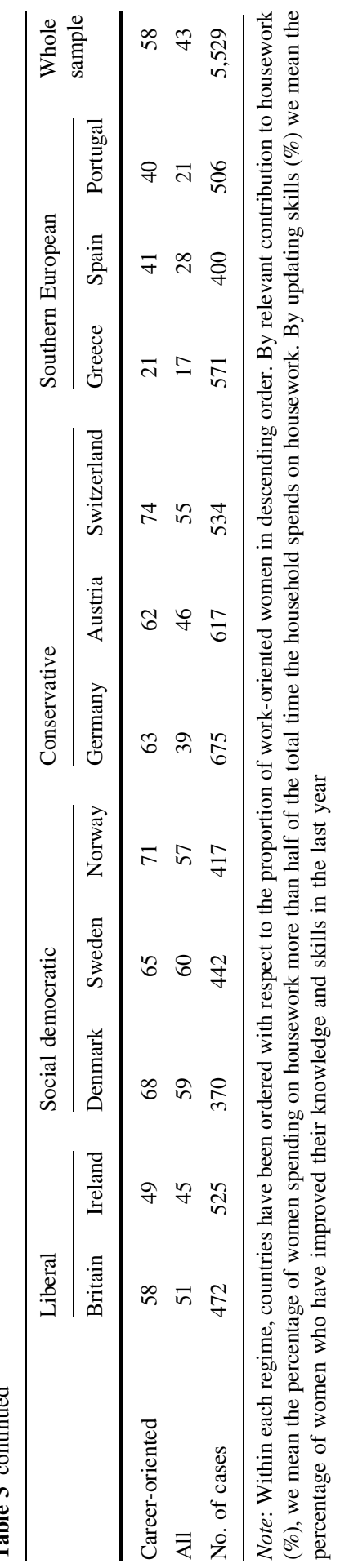




\section{Lifestyle Preferences and Fertility: Hypotheses and Methods}

We have shown that the classification of women according to lifestyle preferences shows consistent patterns of association with behaviour and is associated with welfare regimes. Now we turn to our main research question: can Preference Theory help explain differences in actual and intended fertility? To give a positive answer to such a question, we would expect family-oriented women to have the largest family size and/or to be the most willing to have a(nother) birth, since, by definition, they choose family life and children as their main priority. On the other hand, we would expect career oriented to be the least fertile, as Preference Theory predicts childless women to be concentrated within this group, and the least willing to have a(nother) child, since, by definition, this group centres its life on working activities. Adaptive women should lie in between.

To test whether Hakim's classification is associated with actual and intended fertility, we perform multivariate regression analyses. In order to study the association with actual fertility, we estimate, separately for each country, an ordered logistic model where the dependent variable is the number of children ever had $(0,1,2,3+$, with retrospective reporting). All respondents for whom the information on children ever had is missing are excluded from our analyses. Whenever this model turns out to violate the parallel regression assumption (i.e. that the effect is not parity-specific), we apply a generalized ordinal logistic model (with parity-specific effects). In a first set of models (labelled as Model 1), we only include Hakim's classification of women as an explanatory variable. In all models, adaptive women constitute the reference category. In a second set of models (Model 2), we add further explanatory variables: age, educational level (i.e. number of years of full-time education completed, centred around the individual country mean, thus controlling for country-specific educational systems), work status, educational enrolment and partnership status.

To study the association with intended fertility, we estimate a logistic regression model that models the probability that the respondent intends to have a child within the next 3 years (vs. not intending to have a child). ${ }^{10}$ The exact question used in the survey is: "Do you plan to have a child within the next 3 years?" Respondents could choose between four answers: "definitely not," "probably not," "probably yes" and "definitely yes," or they could refuse to answer, or simply answer that they did not know. All respondents, for whom the information on fertility intentions is missing, are excluded from our analyses. We collapse the answers into two categories: the intention not to have a child within the next 3 years encompasses the answers "definitely not" and "probably not," while the remaining two answers, "probably yes" and "definitely yes" are collapsed into a second category indicating the intention to have a child within the next 3 years. In a first set of models (Model 1), fertility intentions are studied as a function of lifestyle preferences, while controlling for parity (we distinguish between childless women, women with one child (reference category), and women who already had two or more births). In a

\footnotetext{
10 A closer correspondence between fertility intentions and behaviours may be achieved when intentions refer to an explicit time interval (Miller and Pasta 1995).
} 
second set of models (Model 2), we add the set of covariates that we also include in the models for actual fertility. In all regressions, we apply weights that are inverse to the probability of being included in the sample.

\section{Lifestyle Preferences and Fertility: Results}

\subsection{Lifestyle Preferences and Actual Fertility}

The following results have to be interpreted carefully, in terms of association between lifestyle preferences and actual fertility, rather than in terms of a causal relationship from preferences to actual fertility. If the association patterns were consistent with Preference Theory, we should be able to find the "footprints" of lifestyle preferences on actual fertility, using the term of Surkyn and Lesthaeghe (2004). Descriptive results are shown in Table 4. According to the Preference Theory, childlessness should be, on average, higher in the group of career-oriented women as compared to the family-oriented women and, to a smaller extent, also to adaptive women. Indeed, the proportion of childless belonging to the work-oriented group is more than $10 \%$ higher than that belonging to the family-oriented group. However, our data suggest that there is no relevant difference in the proportion of childlessness between adaptive and work-oriented women: respectively 47 and $48 \%$ of respondents turn out to be childless. Similarly, women with one child represent 19 and $21 \%$ for adaptive and family-oriented categories, respectively, while the proportion is slightly higher in the career-oriented group (23\%). Lifestyle preferences are more closely associated with higher parities. The proportion of women with "large" families, i.e. three or more children, is higher among family oriented as compared to the other two types: 16 against $11 \%$ among the adaptive group, and only $8 \%$ among the careerists.

Tables 5 and 6 show the estimates from the ordered logit models, where the response variable is the actual number of children. Table 5 refers to the countries where the ordered logit model is applied, while Table 6 gives the estimates of generalized ordered logit models used for the countries where the hypothesis of proportional regressions turns out to be violated (i.e. covariates have a parityspecific effect). ${ }^{11}$

In Model 1, being family oriented is almost always positively associated with actual family size. The only exceptions are Ireland, where both work and family orientations are positively associated with actual fertility, Sweden and Denmark, where the association with preferences, although consistent with the "footprints" of Preference Theory, is not statistically significant. Great Britain is the only country

\footnotetext{
11 We found that the parallel regression assumption is not violated if the ordered logit models are run on the sub-sample of women with at least one child, thus suggesting that passing from parity zero to parity one is very different from experiencing other transitions, as shown in other studies (Testa and Grilli 2006). However, this solution implies a considerable reduction of the sample size and excludes from the analysis a significant proportion of work-oriented women who, according to Preference Theory, are frequently childless. We therefore decided to estimate generalized ordered models, which do not impose the constraints of parallel regression.
} 


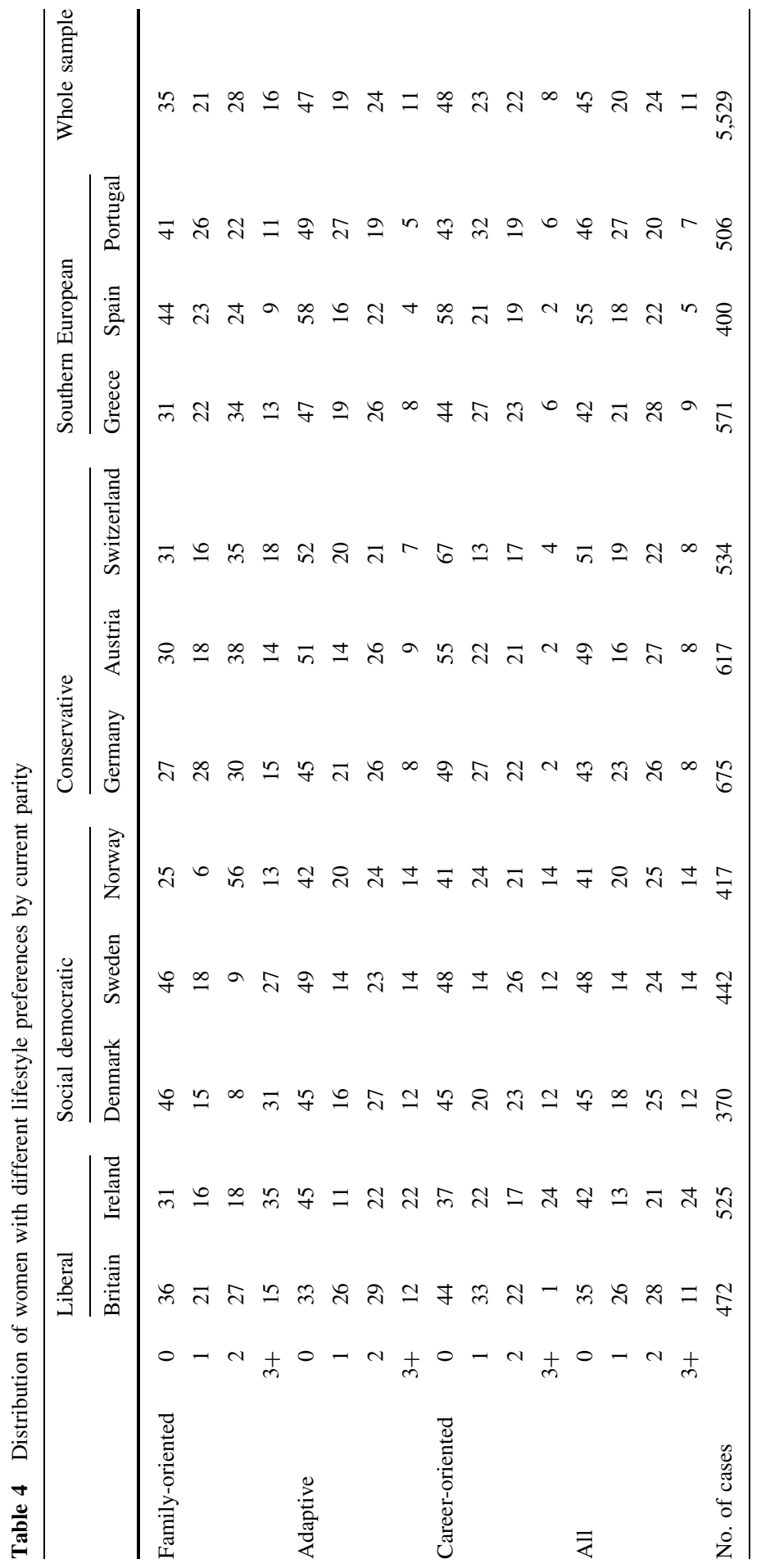




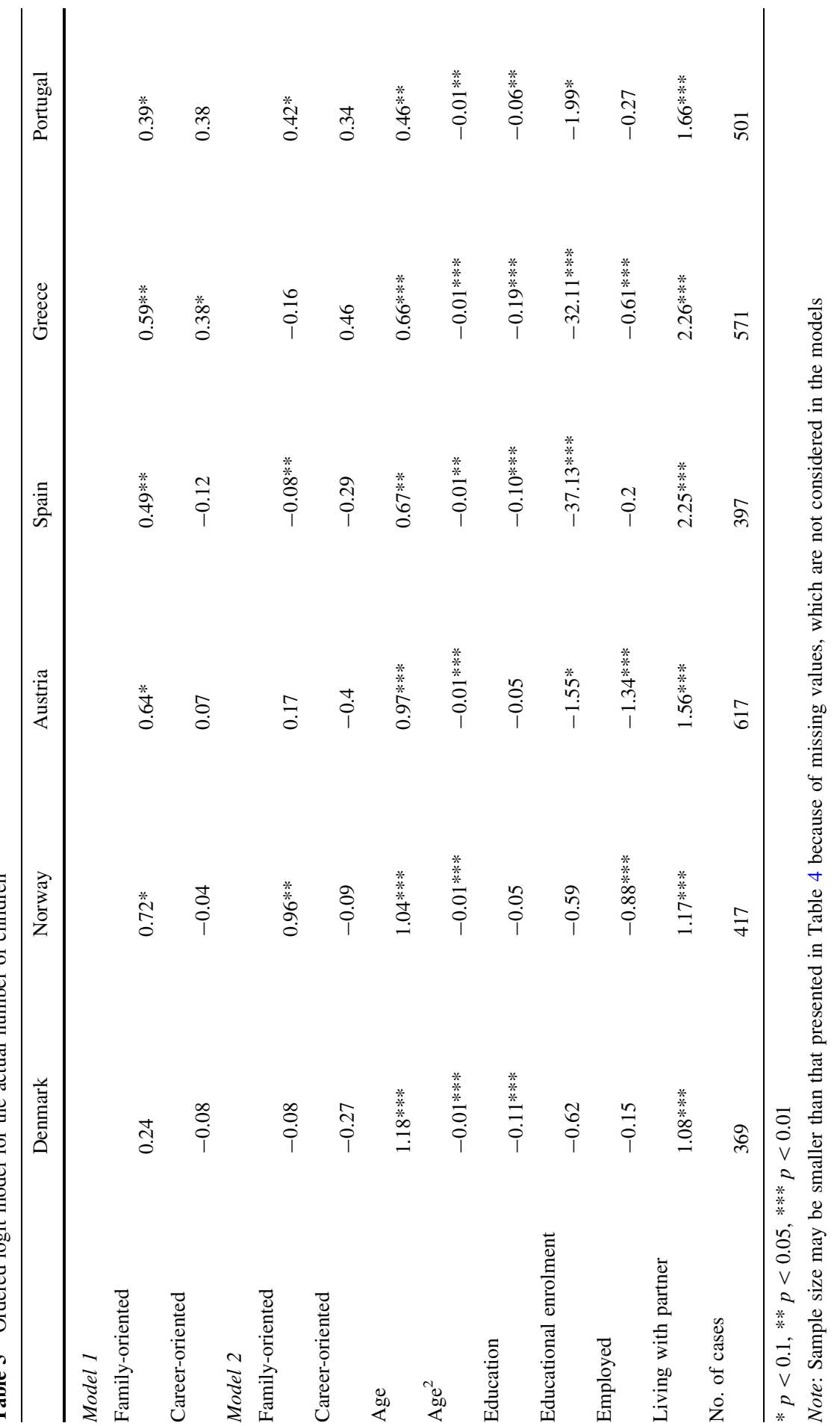




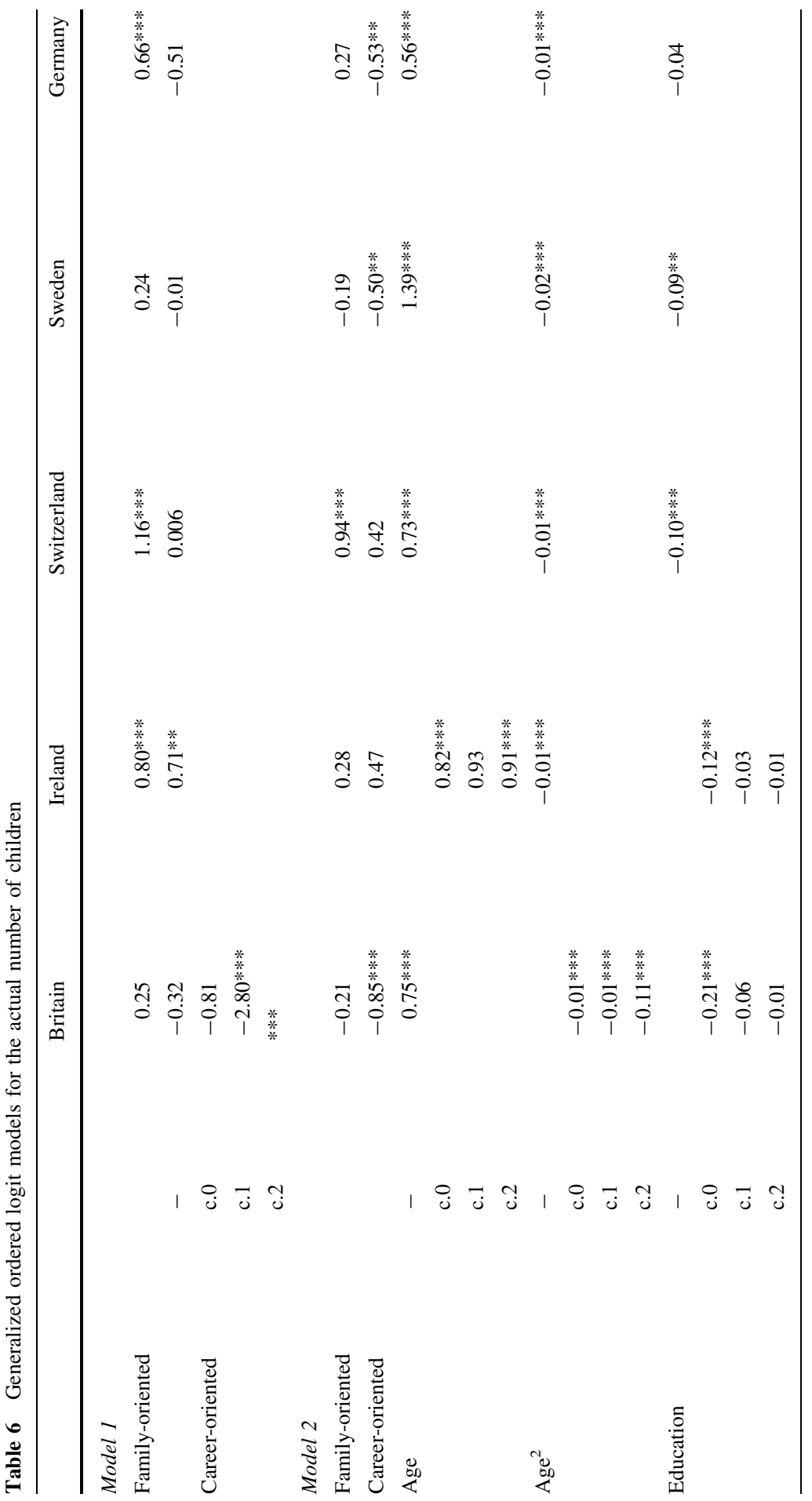




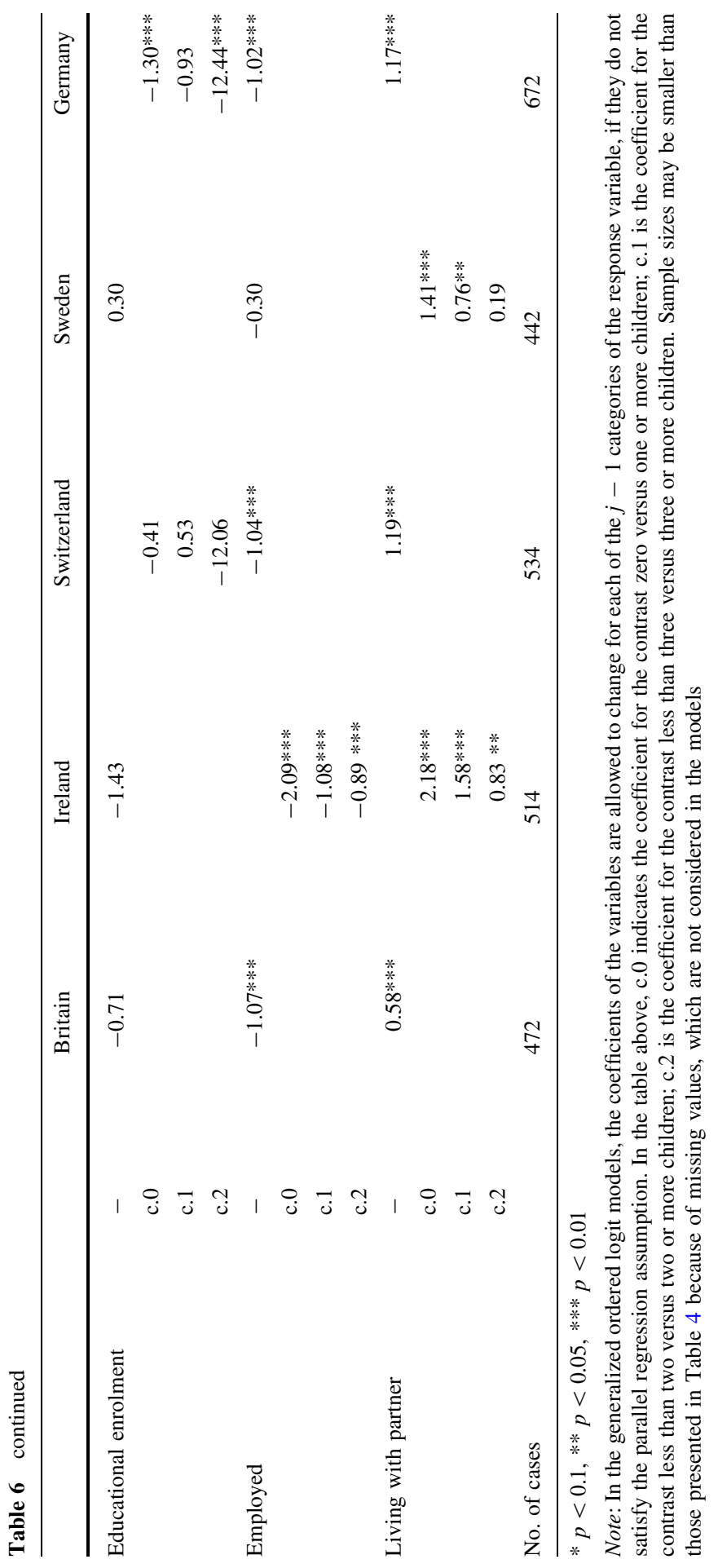


for which the hypothesis of parallel regression is violated, and the negative association between being career oriented and actual family size is significant only for higher parities, i.e. two or more children.

In the second set of models (Model 2), the association between lifestyle preferences and actual fertility is consistent with Preference Theory in Norway, Austria and Germany. However, the parameters of the model are statistically significant only for family-oriented women in Norway and for career-oriented women in Germany. In the other countries, parameter estimates run in a direction that is (even) opposite to that expected from Preference Theory, but they do not significantly differ from zero. Results consistent with Hakim's theory are found in Great Britain, Sweden and Germany. In this latter group of countries, careeroriented women are significantly less likely to have large families than the adaptive group. Results are consistent with Preference Theory also for Norway, Portugal and Switzerland, where family-oriented women are more likely to have families with many children.

These results reveal that in some European countries lifestyle preferences are significantly associated with actual fertility, while in some other countries they are not. Moreover, the association between preferences and actual fertility does not reflect the classification of countries according to the welfare regime typology. In many cases, the significant main effect of lifestyle preferences disappears once other socio-demographic covariates are taken into account, suggesting that lifestyle preferences do not contain additional information with respect to other variables that measure "structural" socio-demographic factors, or that the effect of lifestyle preferences is mediated by other life-course choices. Additional variables, like union status, educational attainment, employment status or educational enrolment, are all consistently associated with actual fertility.

\subsection{Lifestyle Preferences and Intended Fertility}

As fertility intentions can be considered a prerequisite for fertility behaviour, we would expect lifestyle preferences to have an effect on intended fertility if a link existed between preferences and behaviour. We therefore consider the test of Preference Theory on fertility intention as more stringent than the one on actual fertility. Table 7 shows the proportions of different women, as classified according to lifestyle preferences, intending to have a child within the next 3 years.

Interestingly, only in Great Britain are family-oriented respondents more often intending to have a child in the near future, as compared to women with different lifestyle preferences in the same country (see the first column within each preference group in Table 7). In contrast to what one would expect according to Preference Theory, in all the other countries considered we find a higher proportion of careeroriented women who have short-term fertility plans, as compared to the other two groups (adaptive and family oriented). This finding should be taken with some caution due to the selection process that may cause career-oriented women to postpone their actual childbearing more often than the other women. The postponement of actual childbearing would explain why there is a larger group within the career-oriented women - that are also on average at lower parities — wanting a child. Indeed, when we 
Table 7 Distribution of women with different lifestyle preferences and positive short-term fertility intentions

\begin{tabular}{|c|c|c|c|c|c|c|c|c|c|c|c|c|c|}
\hline & \multicolumn{3}{|c|}{ Family-oriented } & \multicolumn{3}{|c|}{ Adaptive } & \multicolumn{3}{|c|}{ Career-oriented } & \multicolumn{3}{|l|}{ All } & \multirow[t]{2}{*}{ No. of cases } \\
\hline & All & 0 & $1+$ & All & 0 & $1+$ & All & 0 & $1+$ & All & 0 & $1+$ & \\
\hline \multicolumn{14}{|l|}{ Liberal } \\
\hline Britain & 21 & 40 & 11 & 20 & 33 & 14 & 15 & 17 & 14 & 20 & 30 & 14 & 472 \\
\hline Ireland & 13 & 9 & 15 & 17 & 16 & 19 & 27 & 45 & 16 & 18 & 18 & 18 & 525 \\
\hline \multicolumn{14}{|c|}{ Social democratic } \\
\hline Denmark & 23 & 33 & 14 & 22 & 30 & 17 & 29 & 46 & 16 & 25 & 36 & 16 & 370 \\
\hline Sweden & 27 & 40 & 17 & 25 & 27 & 22 & 28 & 36 & 21 & 26 & 30 & 22 & 442 \\
\hline Norway & 12 & 0 & 17 & 28 & 32 & 26 & 27 & 38 & 19 & 27 & 33 & 24 & 417 \\
\hline \multicolumn{14}{|l|}{ Conservative } \\
\hline Germany & 11 & 18 & 8 & 14 & 20 & 9 & 20 & 27 & 13 & 15 & 21 & 10 & 675 \\
\hline Austria & 17 & 5 & 23 & 18 & 23 & 13 & 18 & 27 & 8 & 18 & 23 & 14 & 617 \\
\hline Switzerland & 18 & 37 & 9 & 28 & 33 & 23 & 23 & 33 & 17 & 27 & 33 & 21 & 534 \\
\hline \multicolumn{14}{|c|}{ Southern European } \\
\hline Greece & 30 & 55 & 18 & 20 & 22 & 18 & 33 & 51 & 19 & 25 & 33 & 18 & 571 \\
\hline Spain & 25 & 24 & 25 & 23 & 26 & 19 & 34 & 45 & 18 & 25 & 29 & 21 & 400 \\
\hline Portugal & 18 & 16 & 19 & 22 & 31 & 13 & 26 & 30 & 23 & 21 & 27 & 16 & 506 \\
\hline Whole sample & 20 & 27 & 17 & 21 & 26 & 17 & 26 & 36 & 17 & 22 & 28 & 17 & 5,529 \\
\hline
\end{tabular}

Note: The table reports the percentages of women expressing positive fertility intentions. The first column (All) within each preference group refers to women at all parities, the second column (0) refers to women at parity zero while the third column (1+) refers to women at parity one or more. Women with positive fertility intentions are those answering "probably yes" or "definitely yes" to the survey question on the intention to have a child within the next 3 years. Sample sizes may be smaller than those presented in Table 4 because of missing values

analyze childless women and women with at least one child separately, we get results that are more consistent with the Preference Theory: family-oriented women are more likely to plan a child than career-oriented women (see the second and third columns within each preference group in Table 7).

Descriptive data suggest the existence of a large variation in short-term fertility intentions among countries belonging to the same welfare regime while they do not show relevant within-country differences between the three groups of women. The only remarkable exception is Great Britain, the country in which childless careeroriented women seem to be less likely to intend to have a child within the next 3 years. For a more careful analysis, multivariate regressions are needed. When we look at estimates from the logit model (Table 8), we get a similar picture. Covariates related to lifestyle preferences are not statistically significant either in the models that control for parity only (Model 1), or in models that control for several socio-demographic factors (Model 2). The only relevant exceptions are Denmark and Great Britain. In the Danish case, family-oriented women are more likely to intend to have a(n additional) child within the next 3 years, while the British career-oriented women are less likely to intend to have a child within the 


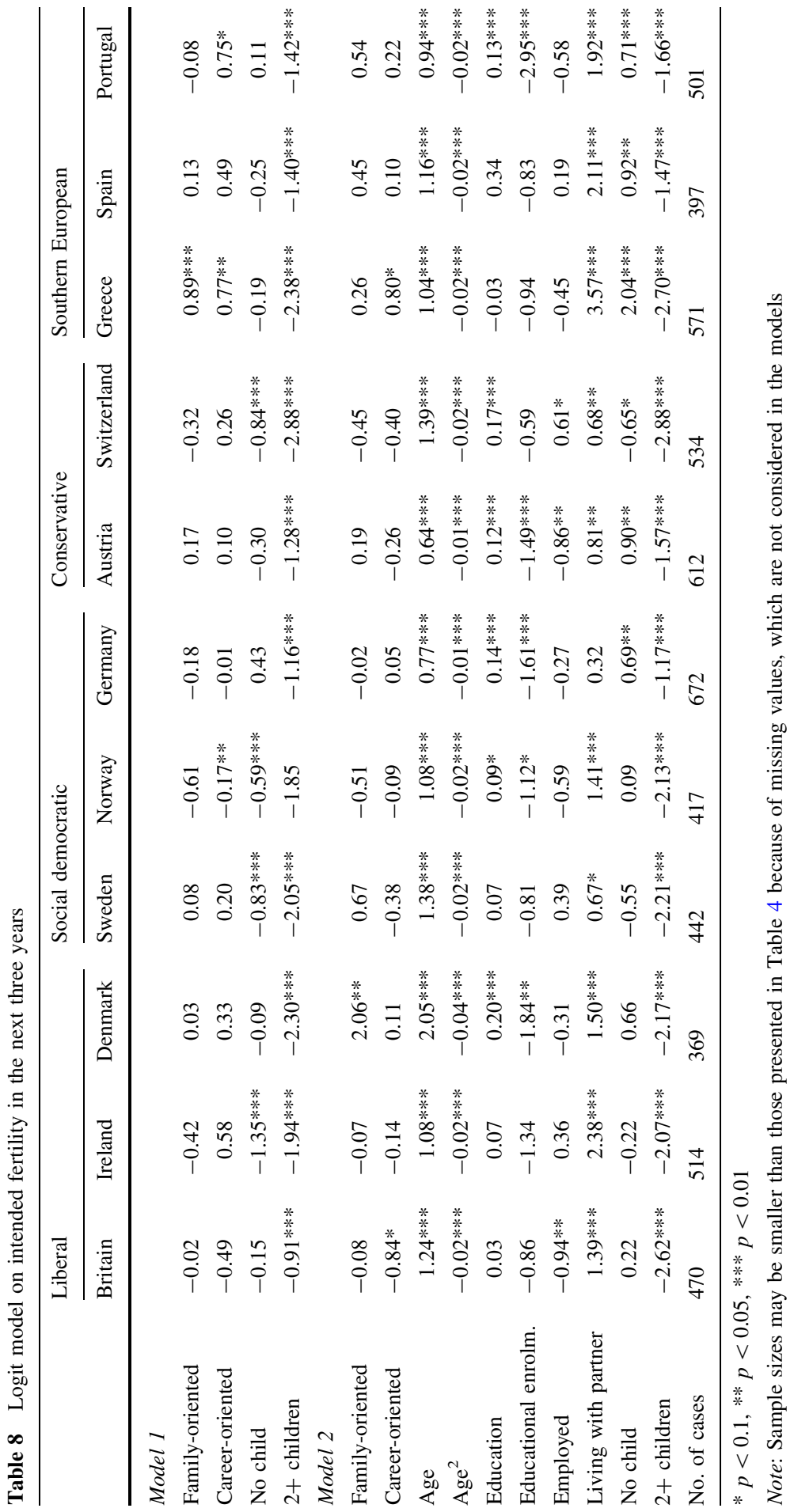


next 3 years, once the effect of background variables is controlled for. ${ }^{12}$ It is worth noting that in Denmark, unlike Britain, the percentage of women with positive fertility intentions shows no significant differences across the three groups of women (Table 7). In the same way, the percentage of Danish women at different parities shows no significant differences across the three groups (Table 4); moreover, Denmark departs also from the identification of the three divergent types of women according to a variety of external characteristics (Table 3). For this reason, the case of Denmark cannot be considered as consistent with Preference Theory. For what concerns the other countries, some results are even inconsistent with the Theory: for example, in Greece work-oriented women are more likely to plan a child in the near future.

\section{Concluding Remarks}

In this paper, we studied the Preference Theory approach proposed by Catherine Hakim focusing on Western European countries. We have provided some evidence that Hakim's Preference Theory is able to identify three different categories of women with respect to their lifestyle preferences toward family or work in a variety of European societies. Moreover, we showed that heterogeneity in lifestyle preferences is mirrored differently in different societies and in different welfare state regimes. Our results of both Social Democratic and Southern European countries also demonstrate that welfare states may bias feminine preference orientations, as suggested by the Preference Theory approach.

We have documented an association between women's lifestyle preferences as described by Hakim's Preference Theory and actual fertility in many of the European settings considered in the analysis. Family-oriented women are the most fertile, while work-oriented women are the least fertile if compared to other women in the sample, even though, after controlling for other background variables, the effect of lifestyle preferences on achieved fertility is, in some cases, absorbed by other factors. If we consider that the relative size of the three female groups varies greatly across countries, this last result seems to suggest that the country-specific compositional effect might explain some variation in the actual fertility levels across countries.

When we evaluated the importance of the same categorization in the fertility decision-making process, through an analysis of the determinants of fertility intentions, results do not support the view that lifestyle preferences explain current fertility choices in the European setting, with the exception of Britain and Denmark. The positive relationship found in the Danish sample between preferences toward the family and short-term fertility plans could, however, be misleading since

\footnotetext{
12 This negative effect of being career oriented on fertility intentions in Britain becomes even higher if we run the same set of models only on the sub-sample of women living in a union, who-according to Hakim-should also have more clear life preferences. In other words, among married or cohabiting women, the consistency of the Preference Theory increases in the case of Britain, while the effect is lost in the case of Denmark. Results for these models are not shown because of the considerable reduction of the sample size they involve.
} 
Denmark does not support the existence of any association between preferences and actual fertility, employment status and cohabitation status.

Thus, Great Britain, the country regarded by Hakim as the most suitable environment to test the Theory on the basis of the achievement of the new scenario for women and the provision of neutral public polices, behaves differently from any other country involved in this study. A general reason why we do not find an association between lifestyle preferences and intended fertility might be the selection process: childlessness is very frequent among career-oriented women and these women are also the most willing to have a(n additional) birth in the near future. This suggests that career-oriented women could have short-term fertility plans because they have not had a child yet, as a result of consequent postponements, more frequent for them than for family-oriented women, who, instead, may not intend to have a birth in the short term, since they already have children, and maybe they have already reached their ideal family size.

Another possible explanation of our results is that lifestyle preferences are more influenced by actual fertility than vice versa. Work-family preferences could be the result and not the cause of fertility. In this case, it would be consistent to only find a relation between lifestyle preferences and realized fertility-this would explain the difference between the results on actual and intended fertility. To fully test this hypothesis, we would need longitudinal data in order to identify the formation of lifestyle preferences during the life course, and in particular possibly as a consequence of fertility choices.

Finally, we have documented the existence of strong heterogeneity among welfare regimes in terms of the relationship between work-family lifestyle preferences and both actual and intended fertility. In all regimes, it is possible to find countries where either family-oriented women are more likely to achieve higher parities if compared to adaptive women or work-oriented women are more likely to achieve lower parities, while there are countries belonging to different welfare regimes where heterogeneous preference orientations are not associated with heterogeneous fertility behaviours. This finding suggests the relevance of countryspecific differences in the association patterns between lifestyle preferences and fertility which go beyond the existing similarities among welfare regimes.

Acknowledgements This research has been funded by the European Commission (DG Employment, Social Affairs and Equal Opportunities) under the Project "Fertility intentions and outcomes: The role of policies to close the gap" (VS/2006/0685). The main parts of the paper were written while the first author visited the Vienna Institute of Demography. We are grateful to Laurent Toulemon for comments and suggestions, as well to the participants of the 2007 Annual Conference of the Population Association of America (New York) and to the "Demosoc" seminar at the Universitat Pompeu Fabra, Barcelona for useful comments.

\section{References}

Aassve, A., Billari, F. C., \& Piccarreta, R. (2007). Strings of adulthood: A sequence analysis of young British women's work-family trajectories. European Journal of Population, 23, 369-388.

Adsera, A. (2005). Where are the babies? Labour market conditions and fertility in Europe. IZA Discussion Paper 1576. 
Ahn, N., \& Mira, P. (2002). A note on the changing relationship between fertility and female employment rates in developed countries. Journal of Population Economics, 15, 667-682.

Beets, G., Liefbroer, A. C., \& de Gierveld, G. Jong. (1999). Changes in fertility values and behaviour: A life course perspective. In R. Leete (Ed.), Dynamics of values in fertility change (pp. 100-120). Oxford: Clarendon Press.

Butz, W. P., \& Ward, M. P. (1979). The emergence of countercyclical U.S. fertility. American Economic Review, 69, 318-328.

Caldwell, J. C., \& Schindlmayr, T. (2003). Explanations of the fertility crisis in modern societies: A search for commonalities. Population Studies, 57(3), 77-92.

Castles, F. G. (2003). The world turned upside down: Below replacement fertility, changing preferences and family-friendly public policy in 21 OECD countries. Journal of European Social Policy, 13(3), 209-227.

Commission of the European Communities. (2005). Green Paper "Confronting demographic change: A new solidarity between the generations". Brussels: Commission of the European Communities.

Crompton, R., \& Harris, F. (1998). Explaining women's employment patterns: 'Orientations to work' revisited. British Journal of Sociology, 49(1), 118-136.

Demeny, P. (2003). Population policy dilemmas in Europe at the dawn of the twenty-first century. Population and Development Review, 29(1), 1-28.

Doorewaard, H., Hendrickx, J., \& Verschuren, P. (2004). Work orientations of female returners. Work, Employment and Society, 18(1), 7-27.

Esping-Andersen, G. (1990). The three worlds of welfare capitalism. Cambridge: Polity Press.

Esping-Andersen, G., Gallie, D., Hemerijk, A., \& Myles, J. (2002). Why we need a new welfare state. Oxford: Oxford University Press.

Fagan, C. (2001). Time money and gender order: Work orientations and working-time preferences in Britain. Gender, Work and Organization, 8(3), 239-266.

Ferrera, M. (1998). Le Trappole del welfare. Bologna: Il Mulino.

Ferrera, M., Hemerijk, A. \& Rhodes M. (2000). The future of the European welfare state: Managing diversity for a prosperous and cohesive Europe. Report for the Portuguese Presidency of the European Union, Conference on Europe, Globalization and the Future of Social Policy.

Gauthier, A. H. (2002). Family policies in industrialized countries: Is there convergence. Population, 57(3), 447-474.

Hakim, C. (2000). Work-lifestyle choices in the 21st century: Preference theory. Oxford: Oxford University Press.

Hakim, C. (2002). Lifestyle preferences as determinants of women's differentiated labour market careers. Work and Occupations, 29(4), 428-459.

Hakim, C. (2003a). Models of the family in modern societies: Ideals and realities. Aldershot: Ashgate.

Hakim, C. (2003b). A new approach to explaining fertility patterns: Preference theory. Population and Development Review, 29(3), 349-374.

Hakim, C. (2003c). Public morality versus personal choice: The failure of social attitude surveys. British Journal of Sociology, 54(3), 339-345.

Hakim, C. (2008). Diversity in tastes, values, and preferences: Comment on Jonung and Ståhlberg. Econ Journal Watch, 5(2), 204-218.

Kohler, H. P., Billari, F. C., \& Ortega, J. A. (2002). The emergence of lowest-low fertility in europe during the 1990s. Population and Development Review, 28(4), 641-681.

Lesthaeghe, R. (1983). A century of demographic and cultural change in Western Europe: An exploration of underlying dimensions. Population and Development Review, 9(3), 411-435.

Lesthaeghe, R., \& Surkyn, J. (1988). Cultural and economic theories of fertility change. Population and Development Review, 13(1), 1-45.

McDonald, P. (2002). Sustaining fertility through public policy: The range of options. Population, 57(3), 417-446.

McRae, S. (2003a). Constraints and choices in mothers' employment careers: A consideration of Hakim's Preference Theory. British Journal of Sociology, 54(3), 317-338.

McRae, S. (2003b). Choices and constraints in mothers' employment careers: McRae replies to Hakim. British Journal of Sociology, 54(4), 585-592.

Miller, W. B., \& Pasta, D. J. (1995). Behavioural intentions: Which ones predict fertility behaviour in married couples? Journal of Applied Social Psychology, 25, 530-555.

Procter, I., \& Padfield, M. (1999). Work orientations and women's work: A critique of Hakim's theory of the heterogeneity of women. Gender, Work and Organization, 6(3), 152-162. 
Rabušic, L. C. \& Manea, B. E. (2006). Preference Theory-The case of the Czech Republic. Paper for the European Population Conference in Liverpool, UK, 21-24 June 2006.

Reher, D. S. (1998). Family ties in Western Europe: Persistent contrasts. Population and Development Review, 24(2), 203-234.

Rose, M. (2001). Closing down a work career. Housework, employment plans, and women's work attitudes. ESRC Working Paper 1. Transitions and Careers, University of Bath.

Stark, L., \& Kohler, H. P. (2002). The debate over low fertility in the popular press: A cross-national comparison, 1998-1999. Population and Policy Review, 21(6), 535-574.

Surkyn, J. \& Lesthaeghe, R. (2004). Value orientations and the second demographic transition (SDT) in Northern, Western and Southern Europe: An update. Demographic Research. Special Collection 3, Article 3. Online available at: http://www.demographic-research.org/.

Testa, M. R., \& Grilli, L. (2006). The influence of childbearing regional contexts on ideal family size in Europe. Population, 61(1-2), 109-138.

Tomlinson, J. (2006). Women's work-life balance trajectories in the UK: reformulating choice and constraint in transitions through part-time work across the life-course. British Journal of Guidance and Counselling, 34(3), 365-382.

Van de Kaa, D. J. (1987). Europe's second demographic transition. Population Bulletin, 42(1), 1-57. 